\title{
Enhancement of Optimal Scheduling and Fuel Cost Minimization using Flexible Genetic Algorithm
}

\author{
Ch. Srinivas \\ Assistant Professor \\ Department of Electrical and Electronics Engineering \\ D.M.S.S.V.H. College of Engineering \\ Machilipatnam
}

\begin{abstract}
This paper aims at providing a solution to optimum power flow (OPF) in considered power systems by using a flexible genetic algorithm (GA) model. The proposed approach finds the optimal setting of OPF control variables which include generator active output, generator bus voltages, transformer tap-setting and shunt devices with the objective function of minimizing the fuel cost. The proposed GA is modeled to be flexible for implementation to any power systems with the given system line, bus data, generator fuel cost parameter and forecasted load demand. The GA model has been analyzed and tested on the standard benchmark IEEE 30-bus system and two real time power systems which are an industrial park power system and a gold-copper mining power system both located in Indonesia. The results obtained outperform other approaches which are recently applied to the IEEE 30-bus system with the same control variable maximum \& minimum limits and system data. Better results are also found when compared against the configurations used in the two real power systems. These superior results are achieved due to the robust and reliable algorithm of the proposed GA which utilizes the differential evaluation.
\end{abstract}

\section{General Terms}

Optimal power flow, Fuel cost minimization, Genetic algorithm, Differential Evaluation.

\section{Keywords}

Cross-over, mutation, Genetic algorithm, flexible genetic algorithm, Non-smooth cost functions, optimal power flow (OPF).

\section{INTRODUCTION}

In power system operation and planning, optimum power flow is one of the areas in which power engineers focus on in order to minimize the operational cost and system losses, while supplying reliable and uninterruptible electricity to the consumers. Power plant management is required not only to provide uninterruptible and reliable power supply but also to achieve the most economic cost. By optimizing the power flow and concurrently minimizing the operational cost and taking into account the power losses, these objectives can be achieved. Furthermore, by utilizing the evolutionary-based approach specifically the Genetic Algorithm (GA), the Optimum Power Flow (OPF) will be relatively easier and faster to be analyzed and solved. No. of optimization are proposed to control the power flow solutions. Since the optimum power flow method was first introduced by Dommel and Tinney in 1968[1]. The major techniques are linear programming, quadratic programming, weighting, surrogate worth tradeoff techniques. To simplify the OPF problem many mathematical assumptions are used, like convex, analytical, differential objective functions [1].
Now the interest is changed in OPF from mathematical programming algorithms to evolutionary programming methods. The advancement in optimal power flow problem solving the genetic algorithm is applied as direct \& integration with other techniques is introduced to obtained promising results. In this processes the tabu search \& PSO algorithm are introduced for OPF problem to get the best results by avoiding the limitations of mathematical programming approaches.

In PSO the search technique having multi agents in a parallel combination. Das et al proposed a new scheme, adjustment of velocity of particles in PSO using the tool, called a vector differential operator. The random selection is used for mutation in the name of base vector. In these processes best vector is chosen as the base vector for mutation processes (i.e., random selection of base vector). In this paper a hybrid intelligent algorithm is used as an effective approach to solve the OPF problem in the view to minimization of fuel cost. IEEE-30 bus standard test system is chosen to demonstrate the proposed algorithm \& to examine the proposed algorithm to evaluate the performance for getting the optimal global fuel cost. Some commercially available OPF programs use linear programming (LP) optimization techniques. Their overall solution strategy may simply be summarized in several stages:

Stage 1: nonlinear power flow

Stage 2: linearization around a power flow solution

Stage 3: LP optimization

Iterate back to Stage 1

One major limitation of such a strategy is that the LP optimization process cannot proceed when Stage 1 produces no power flow solution.

\section{PROBLEM FORMULATION}

The mathematical formulation of OPF problem can solved as follows:

Mini $\mathrm{F}(x, u)$

Sub to

$$
\begin{aligned}
& \mathrm{g}_{\mathrm{n}}(\mathrm{x}, \mathrm{u})=0 \\
& \mathrm{~h}_{\text {min }} \leq \mathrm{h}(\mathrm{x}, \mathrm{u}) \leq \mathrm{h}_{\max }
\end{aligned}
$$

Where vector $x$ denotes the state variables in vector form for the considered system. The power system contains the slack bus real power output $\left(\mathrm{P}_{\mathrm{G} 1}\right)$, voltage magnitudes and phase angles of the load buses $\left(\mathrm{Vi}, \delta_{\mathrm{i}}\right)$ and generator reactive power outputs $\left(\mathrm{Q}_{\mathrm{G}}\right)$. Vector $u$ represents control variables that consist of real power $\left(\mathrm{P}_{\mathrm{GN}}\right)$ and generator voltages magnitudes $\left(\mathrm{V}_{\mathrm{GN}}\right)$, transformer tap setting $\left(\mathrm{T}_{\mathrm{K}}\right)$ and reactive power injections $\left(\mathrm{Q}_{\mathrm{CK}}\right)$ due to volt-amperes reactive (VAR) compensations: 
$u=[P \mathrm{G} 1 \ldots P \mathrm{GN}, V \mathrm{G} 1 \ldots V \mathrm{GN}, T 1 \ldots T \mathrm{NT}, Q \mathrm{C} 1 \ldots Q \mathrm{CS}]$

Where $N$ is the number of generator buses, NT is the number of tap changing transformers, and CS is the number of shunt reactive power injections.

The OPF problem has two types of constraints:

Equality constraints These are the sets of nonlinear power flow equations that govern the power system, i.e

$$
\begin{aligned}
& \mathrm{P}_{\mathrm{GK}}-\mathrm{P}_{\mathrm{DK}}-\sum_{\mathrm{J}=1}^{\mathrm{N}}\left|\mathrm{V}_{\mathrm{K}}\right|\left|\mathrm{V}_{\mathrm{J}}\right|\left|\mathrm{Y}_{\mathrm{KJ}}\right| \operatorname{COS}\left(\Theta_{\mathrm{KJ}}-\delta_{\mathrm{K}}+\delta_{\mathrm{j}}\right)=0 \\
& \mathrm{Q}_{\mathrm{GK}}-\mathrm{Q}_{\mathrm{DK}}-\sum_{\mathrm{J}=1}{ }^{\mathrm{N}}\left|\mathrm{V}_{\mathrm{K}}\right|\left|\mathrm{V}_{\mathrm{J}}\right|\left|\mathrm{Y}_{\mathrm{KJ}}\right| \operatorname{Sin}\left(\Theta_{\mathrm{KJ}}-\delta_{\mathrm{k}}+\delta_{\mathrm{j}}\right)=0
\end{aligned}
$$

Where $\mathrm{P}_{\mathrm{GK}}$ and $\mathrm{Q}_{\mathrm{GK}}$ are the real and reactive power outputs injected at bus $i$, respectively, the load demand at the same bus is represented by $\mathrm{P}_{\mathrm{DK}}$ and $\mathrm{Q}_{\mathrm{DK}}$, and elements of the bus admittance matrix are represented by $\left|\mathrm{Y}_{\mathrm{Kj}}\right|$ and $\Theta_{\mathrm{Kj}}$.

Inequality constraints These are the set of constraints that represent the system operational and security limits like the bounds on the following:

1) Generators real and reactive power outputs

$$
\begin{aligned}
& \mathrm{P}_{\mathrm{GK}}{ }^{\min } \leq \mathrm{P}_{\mathrm{GK}} \leq \mathrm{P}_{\mathrm{GK}}{ }^{\max }, \mathrm{k}=1, \ldots . \mathrm{N} \\
& \mathrm{Q}_{\mathrm{GK}}{ }^{\min } \leq \mathrm{Q}_{\mathrm{GK}} \leq \mathrm{Q}_{\mathrm{GK}}{ }^{\max }, \mathrm{k}=1, \ldots . \mathrm{N}
\end{aligned}
$$

2) Voltage magnitudes at each bus in the network

$\mathrm{V}_{\mathrm{K}}{ }^{\mathrm{min}} \leq \mathrm{V}_{\mathrm{K}} \leq \mathrm{V}_{\mathrm{K}}{ }^{\max }, \mathrm{k}=1, \ldots . . \mathrm{NL}$

where NL is the number of load buses.

3) Transformer tap settings

$$
\mathrm{T}_{\mathrm{K}}{ }^{\mathrm{min}} \leq \mathrm{T}_{\mathrm{K}} \leq \mathrm{T}_{\mathrm{K}}^{\max }, \mathrm{k}=1, \ldots \ldots \mathrm{NT}
$$

4) Reactive power injections due to capacitor banks

$$
\mathrm{Q}_{\mathrm{CK}}{ }^{\min } \leq \mathrm{Q}_{\mathrm{CK}} \leq \mathrm{Q}_{\mathrm{CK}}{ }^{\max }, \mathrm{k}=1, \ldots . . \mathrm{CS}
$$

In this paper, the constraints corresponding to the state or dependent variables are incorporated into a fitness function.

1) Minimization of generation fuel cost:

In general the OPF generation fuel cost function can be expressed by a quadratic function as follows.

$$
\begin{aligned}
& \operatorname{Mini}(\mathrm{FT})=\sum_{\mathrm{N}=1}^{\mathrm{NG}} \mathrm{F}_{\mathrm{N}}\left(\mathrm{P}_{\mathrm{GN}}\right) \\
& \mathrm{F}_{\mathrm{N}} \mathrm{P}_{\mathrm{GN}}=\mathrm{a}_{\mathrm{N}}+\mathrm{b}_{\mathrm{N}} \mathrm{P}_{\mathrm{GN}}+\mathrm{C}_{\mathrm{N}} \mathrm{P}_{\mathrm{GN}}{ }^{2}
\end{aligned}
$$

2) IEEE 30 bus power system:

The IEEE-30 bus system is taken in this paper to test the proposed algorithm \& it is used as a standard test system to study different power problems \& evaluate programs to analyze such problems. It consists of 6 generator units as well as 41 transmission lines.

\section{PROPOSED ALGORITHM}

The performance $[11,12]$ of the DE algorithm is sensitive to the mutation strategy, crossover strategy and control parameters such as the population size $(N P)$, crossover rate $(C R)$ and the scale factor $(F)$. The proposed flexible genetic algorithm is associated with DE search and it consists of a pool of mutation and crossover strategies along with a pool of values for each of the associated control parameters.

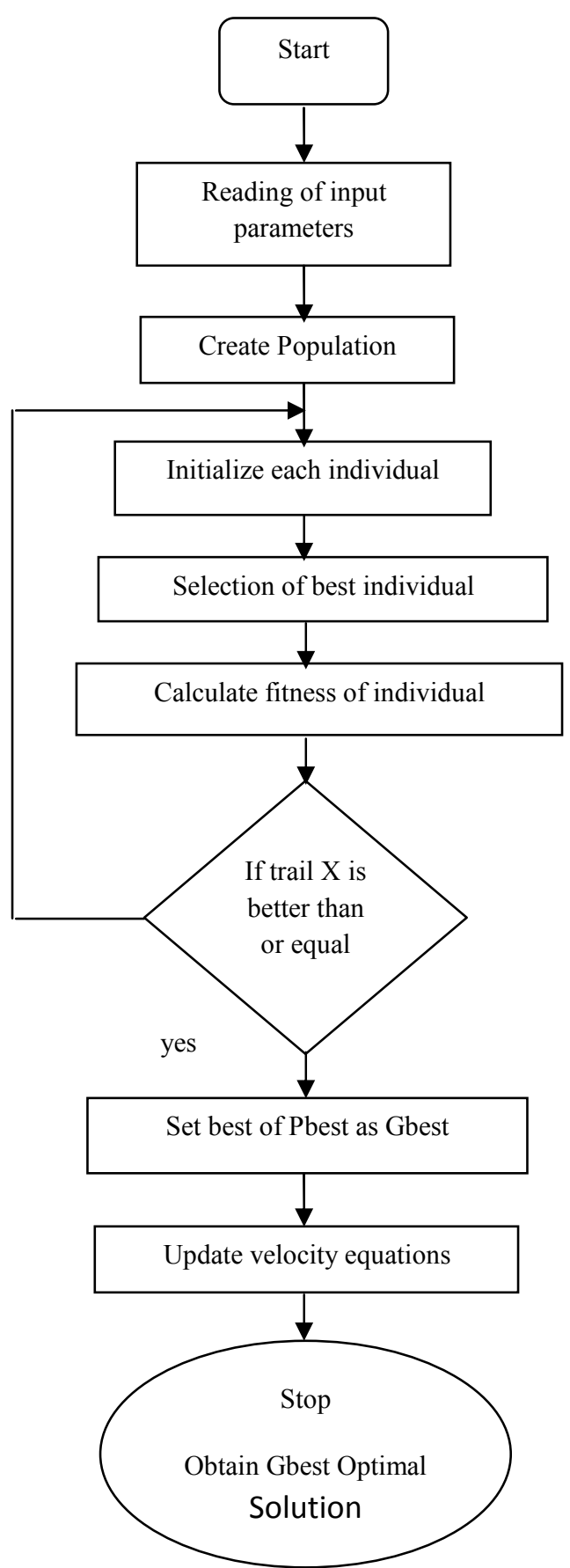

Figure 1: Flow Chart for Proposed Algorithm

Each member in the initial population is randomly assigned with a mutation strategy and associated parameter values taken from the respective pools. The population members (target vectors) produce offspring (trial vectors) using the assigned mutation strategy and parameter values. If the generated trial vector produced is better than the target vector, the mutation strategy and parameter values are retained with trial vector which becomes the parent (target vector) in the next generation. The combination of the mutation strategy and the parameter values that produced a better offspring than the parent are stored. If the target vector is better than the trial vector, then the target vector is randomly reinitialized with a new mutation strategy and associated parameter values from the respective pools or from the successful combinations stored with equal probability. This leads to an increased probability of production of offspring by the better 
combination of mutation strategy and the associated control parameters in the future generations. The initialization of each individual in population creation is represented by following two equations (14) \& (15).

$\operatorname{cost}(1, p p)=\operatorname{cost}(1, p p)+\left(a 1(\right.$ ii $\left.) * \operatorname{Xr}(\text { ii,pp })^{\wedge} 2\right)+($ b1 (ii) $* X r(i i, p p))+$ c1(ii);

fit $(1, p p)=1 / \operatorname{cost}(1, p p)$;

\section{PRATICAL POWER SYSTEMS}

Three practical power systems are considered in this paper as case $1,2,3$

\section{Case 1: Standard IEEE 30-Bus System}

The IEEE-30 bus system network consists of 6 generators buses, 21 load buses and 41 branches of which 4 branches are under load tap setting transformer branches. The generator units are connected to the bus number 1, 2, 5, 8, 11 and 13 . The generator cost coefficients of IEEE-30 bus system are tabulated as follows [1]:

Table 1: generator cost coefficients of IEEE-30 bus system

\begin{tabular}{|c|c|c|c|c|c|}
\hline \multirow{2}{*}{ Bus No } & \multicolumn{3}{|c|}{ Cost Coefficients } & \multirow{2}{*}{$\begin{array}{c}\text { Min } \\
\text { MW }\end{array}$} & $\begin{array}{c}\text { Max } \\
\text { MW }\end{array}$ \\
\cline { 2 - 4 } 1 & $\mathrm{a}$ & $\mathrm{b}$ & $\mathrm{c}$ & MW & \\
\hline 2 & 0.0 & 2.00 & 0.00375 & 50 & 200 \\
\hline 5 & 0.0 & 1.00 & 0.06250 & 10 & 50 \\
\hline 8 & 0.0 & 3.25 & 0.00834 & 10 & 35 \\
\hline 11 & 0.0 & 3.00 & 0.02500 & 10 & 30 \\
\hline 13 & 0.0 & 3.00 & 0.02500 & 12 & 40 \\
\hline
\end{tabular}

\section{Case 2: Industrial Park Power System}

The second test system for proposed method is on a real industrial park power plant which consists of six diesel generators (total $21 \mathrm{MW})$, two generator voltages $(6.6 \mathrm{KV}$ and $11 \mathrm{KV}$ ) and five loads (Substations A, B, C and Powerhouse auxiliaries). Single line diagram of Industrial power plant is shown in figure 2 . While, the total power for the auxiliaries such as fuel system, lubrication oil system and the actual load demand is $10.9 \mathrm{MW}$ [1]

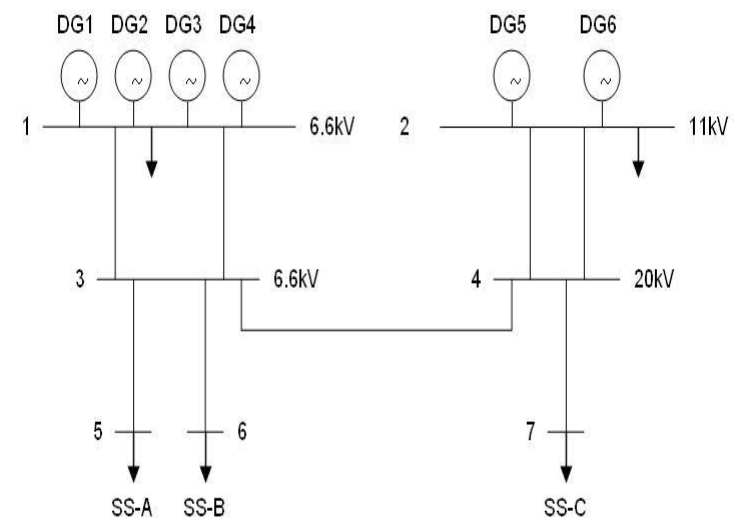

Figure 2: single line diagram of industrial park power system
Table 2: generator cost coefficients of industrial park power system [1]

\begin{tabular}{|c|c|c|c|c|c|}
\hline \multirow{2}{*}{$\begin{array}{c}\text { Unit } \\
\text { No }\end{array}$} & \multicolumn{3}{|c|}{ Cost Coefficients } & \multirow{2}{*}{$\begin{array}{c}\text { Min } \\
\text { Max }\end{array}$} & $\begin{array}{c}\text { Ma } \\
\text { MW }\end{array}$ \\
\hline 1 & 40.54 & 103.01 & 17.61 & 1.05 & 2.1 \\
\hline 2 & 40.30 & 105.03 & 16.71 & 1.05 & 2.1 \\
\hline 3 & 41.59 & 104.20 & 17.08 & 1.05 & 2.1 \\
\hline 4 & 43.46 & 100.50 & 18.12 & 1.05 & 2.1 \\
\hline 5 & 111.73 & 68.01 & 0.0250 & 3.25 & 6.5 \\
\hline 6 & 81.31 & 87.38 & 0.0250 & 3.05 & 6.1 \\
\hline
\end{tabular}

Case 3: Gold-Copper Mine Power System

The large power plant consists of 20 diesel generators (total $80 \mathrm{MW}$ ), 18 loads. The total power load including the auxiliaries such as fuel system, lubrication oil system and mining load demand is $27.56 \mathrm{MW}$. The single line diagram of gold-copper mine power system is depicted in figure 2 .

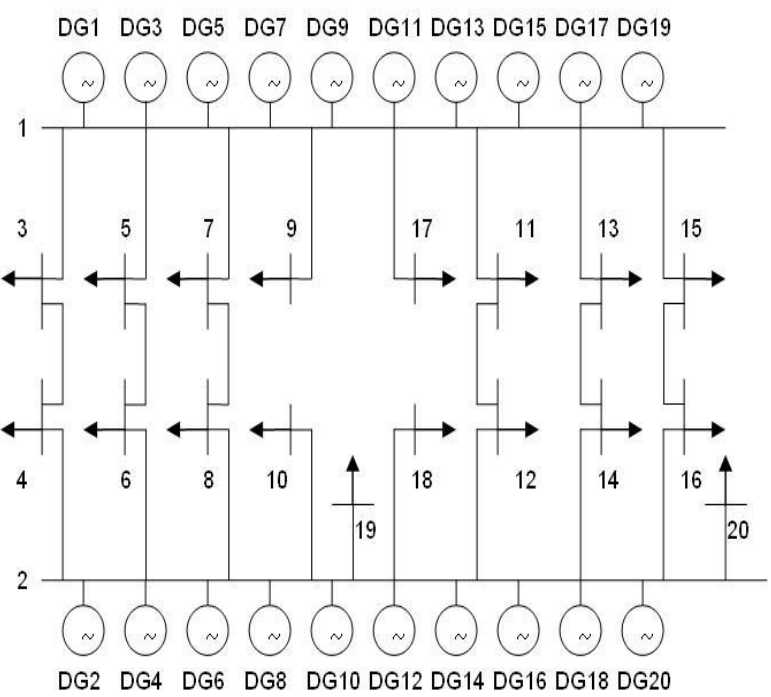

Figure 3: Single line diagram of gold-copper mine power system [1]

Table 3: generator cost coefficient of gold-copper mine power system [1]

\begin{tabular}{|c|c|c|c|c|c|}
\hline \multirow{2}{*}{$\begin{array}{l}\text { Unit } \\
\text { No }\end{array}$} & \multicolumn{3}{|c|}{ Cost Coefficients } & \multirow{2}{*}{$\begin{array}{l}\text { Min } \\
\text { MW }\end{array}$} & \multirow{2}{*}{$\begin{array}{l}\text { Max } \\
\text { MW }\end{array}$} \\
\hline & $\mathrm{a}$ & B & $\mathrm{c}$ & & \\
\hline$* 1$ & 68.96 & 100.64 & 4.79 & 2.0 & 4.0 \\
\hline$*_{2}$ & 174.17 & 2.32 & 24.40 & 2.0 & 4.0 \\
\hline$* 3$ & 169.99 & 5.73 & 25.88 & 2.0 & 4.0 \\
\hline
\end{tabular}




\begin{tabular}{|c|c|c|c|c|c|}
\hline 4 & 39.48 & 114.80 & 2.21 & 2.0 & 4.0 \\
\hline$* 5$ & 169.99 & 5.73 & 25.88 & 2.0 & 4.0 \\
\hline 6 & 194.74 & 0.57 & 25.08 & 2.0 & 4.0 \\
\hline 7 & 188.41 & 8.75 & 25.04 & 2.0 & 4.0 \\
\hline$* 8$ & 107.84 & 71.33 & 10.27 & 2.0 & 4.0 \\
\hline 9 & 169.99 & 5.73 & 25.88 & 2.0 & 4.0 \\
\hline$* 10$ & 176.28 & 21.23 & 20.60 & 2.0 & 4.0 \\
\hline 11 & 169.99 & 5.73 & 25.88 & 2.0 & 4.0 \\
\hline 12 & 136.39 & 52.90 & 15.30 & 2.0 & 4.0 \\
\hline$* 13$ & 169.99 & 5.73 & 25.88 & 2.0 & 4.0 \\
\hline$* 14$ & 128.74 & 44.39 & 16.67 & 2.0 & 4.0 \\
\hline$* 15$ & 146.36 & 48.14 & 15.54 & 2.0 & 4.0 \\
\hline$* 16$ & 144.54 & 38.57 & 18.12 & 2.0 & 4.0 \\
\hline 17 & 181.47 & 9.95 & 23.66 & 2.0 & 4.0 \\
\hline 18 & 146.36 & 48.14 & 15.54 & 2.0 & 4.0 \\
\hline 19 & 18.29 & 121.40 & 0.85 & 2.0 & 4.0 \\
\hline$* 20$ & 38.37 & 114.34 & 1.12 & 2.0 & 4.0 \\
\hline
\end{tabular}

Table 4: Comparison of Optimal Scheduling \& Fuel Cost Results with Proposed, Gradient Based \& Power World Simulator [1]

\begin{tabular}{|c|c|c|c|c|c|}
\hline Units & Min & Max & $\begin{array}{c}\text { Proposed } \\
\text { approach }\end{array}$ & $\begin{array}{c}\text { Gradient } \\
\text { Based[1] }\end{array}$ & $\begin{array}{c}\text { Power } \\
\text { simulat } \\
\text { or[1] }\end{array}$ \\
\hline 1 & 50 & 200 & 156.71 & 187.219 & 197.99 \\
\hline 2 & 20 & 80 & 50.061 & 53.781 & 44.00 \\
\hline 5 & 10 & 35 & 24.78 & 16.955 & 22.00 \\
\hline 8 & 10 & 30 & 13.10 & 11.288 & 10.00 \\
\hline 11 & 15 & 50 & 26.21 & 11.287 & 10.00 \\
\hline 13 & 12 & 40 & 12.00 & 13.353 & 12.00 \\
\hline $\begin{array}{c}\text { Fuel } \\
\text { cost(\$hr) }\end{array}$ & & & $\$ 778.0762$ & $\$ 804.853$ & $\$ 811.5$ \\
\hline
\end{tabular}

Case 2: Industrial Park Power System
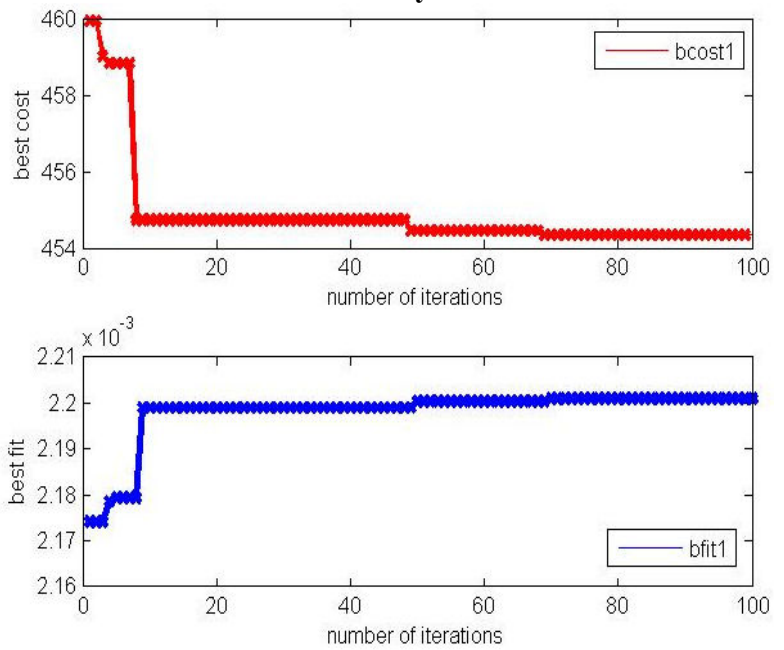

Figure 5: Fuel Cost \& Fitness Values for Industrial Park Power System with Proposed Approach

\section{Case 1: Standard IEEE 30-Bus System}
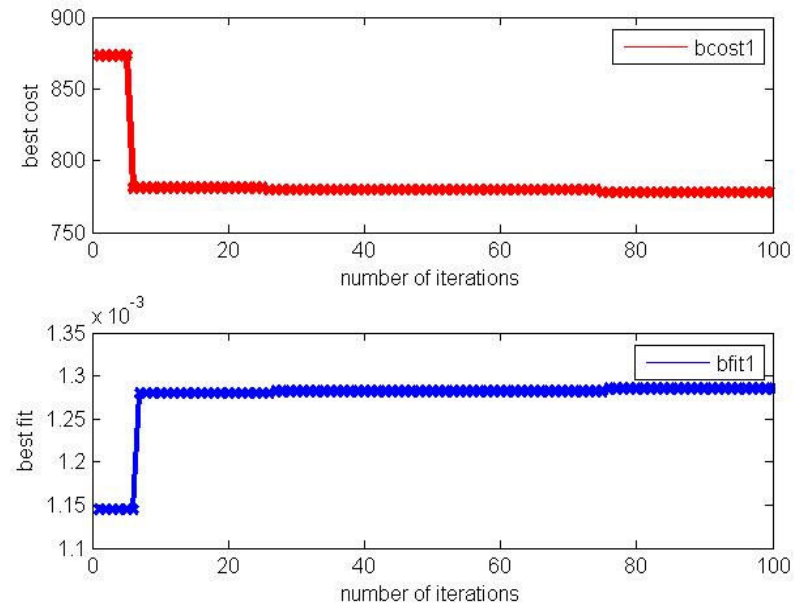

Figure 4: Fuel Cost \& fitness Values for IEEE-30 Bus System with Proposed Approach

Table 5: Comparison of Optimal Scheduling \& Fuel Cost Results with Actual Setting \& Proposed Approach

\begin{tabular}{|c|c|c|c|c|}
\hline Units & Min & Max & $\begin{array}{c}\text { Proposed } \\
\text { approach }\end{array}$ & $\begin{array}{c}\text { Actual } \\
\text { Heuristic [1] }\end{array}$ \\
\hline 1 & 1.05 & 2.1 & 1.1177 & 1.0323 \\
\hline 2 & 1.05 & 2.1 & 1.2565 & 1.4600 \\
\hline 3 & 1.05 & 2.1 & 1.2194 & 1.2190 \\
\hline 4 & 1.05 & 2.1 & 1.1177 & 1.2050 \\
\hline 5 & 3.25 & 6.5 & 3.2500 & --------- \\
\hline 6 & 3.05 & 6.1 & 3.0500 & 6.1000 \\
\hline $\begin{array}{c}\text { Fuel } \\
\text { cost(\$hr) }\end{array}$ & & & $\$ 454.3399$ & $\$ 1,395.03$ \\
\hline
\end{tabular}


Case 3: Gold-Copper Mine Power System
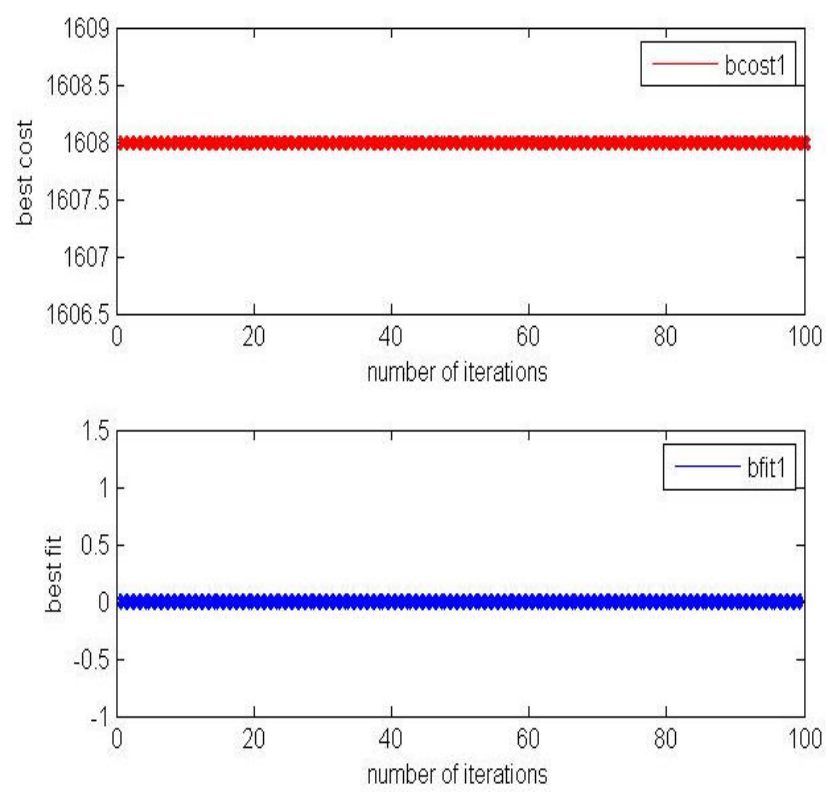

Figure 6: Fuel Cost \& Fitness Values for Gold-Copper Power System with Proposed Approach

Table 6: Comparison of Optimal Scheduling \& Fuel Cost Results with Actual Setting \& Proposed Approach

\begin{tabular}{|c|c|c|c|c|}
\hline Units & Min & Max & $\begin{array}{l}\text { Proposed } \\
\text { approach }\end{array}$ & $\begin{array}{c}\text { Actual } \\
\text { heuristic } \\
{[1]}\end{array}$ \\
\hline 1 & 2.0 & 4.0 & 4.0 & 2.511 \\
\hline 2 & 2.0 & 4.0 & 2.813 & 2.494 \\
\hline 3 & 2.0 & 4.0 & 2.926 & 2.507 \\
\hline 5 & 2.0 & 4.0 & 2.963 & 2.492 \\
\hline 8 & 2.0 & 4.0 & 2.960 & 2.673 \\
\hline 10 & 2.0 & 4.0 & 2.942 & 2.594 \\
\hline 13 & 2.0 & 4.0 & 2.599 & 2.580 \\
\hline 14 & 2.0 & 4.0 & 2.599 & 2.572 \\
\hline 15 & 2.0 & 4.0 & 2.599 & 2.230 \\
\hline 16 & 2.0 & 4.0 & 2.599 & 2.627 \\
\hline 20 & 2.0 & 4.0 & 2.599 & 2.720 \\
\hline $\begin{array}{c}\text { Fuel } \\
\operatorname{cost}(\$ \backslash h r)\end{array}$ & & & $\$ 1,608.3$ & $\$ 3,887.23$ \\
\hline
\end{tabular}

\section{CONCLUSION}

In this paper, the flexible genetic algorithm model has been successfully implemented on the standard IEEE-30 bus system, industrial park power plant and the gold-copper mine power system with actual data \& load demand pattern. The algorithm which was proposed in this paper is modeled to be flexible for implementation to any practical power systems with line\& bus data, generator fuel cost parameter and forecasted load demand. Superior results are obtained by proposed algorithm when compared to the existing methods for the IEEE-30 bus system and two practical power plants named industrial park power system and gold-copper power plants. Any large power network can tested using proposed flexible genetic algorithm because of only the robust and reliability that can be achieved by utilizing differential evaluation. Finally the proposed approach ensure more optimal configuration of control variables, provides a solution with lower operational cost.

\section{REFERENCES}

[1] Irfan mulyawan malik, Optimum power flow using flexible genetic algorithm model in practical power systems thesis for MASTER of Engineering 2010 NATIONAL UNIVERSITY of SINGAPURE.

[2] M. Syai'in, K. L. Lian, N. C. Yang and T. H. Chen, A distribution power flow using particle swarm optimization, IEEE Power and Energy Society General Meeting, pp.1-7, 2012.

[3] P. Acharjee and S. K. Goswami, Chaotic particle swarm optimization based reliable algorithm to overcome the limitations of conventional power ow methods, Proc. of Power Systems Conference and Exposition, 2009.

[4] A. A. A. Esmin, G. Lambert-Torres and A. C. Z. de Souza, A hybrid particle swarm optimization applied to loss power minimization, IEEE Trans. on Power Syst., vol.20, pp.859-866, 2005.

[5] R. Gämperle, S. D. Müller and P. Koumoutsakos, "A parameter study for differential evolution," Advances in Intelligent Systems, Fuzzy Systems, Evolutionary Computation, WSEAS Press, Interlaken, Switzerland, 2002, pp. 293-298.

[6] S. Das, A. Konar and U. K. Chakraborty, Two improved differential evolution schemes for faster global search, Proceedings of the 2005 conference on Genetic and evolutionary computation (2005), 991-998

[7] V. L. Paucar and M. J. Rider, On the use of artificial neural networks for enhanced convergence of the load flow problem in power systems, Proc. of Intelligent Systems Applications to Power Systems, pp.153-158, 2001.

[8] Fröhlich, B. and Plate, J. 2000. The cubic mouse: a new device for three-dimensional input. In Proceedings of the SIGCHI Conference on Human Factors in Computing Systems.

[9] M. S. Osman, M. A. Abo-Sinna, A. A. Mousa, A solution to the optimal power flow using genetic algorithm, Applied Mathematics and Computation. 155 (2004) 391405.

[10] G. Duan, Y. Yu, Problem-specific genetic algorithm for power transmission system planning, Electric Power Systems Research. 61 (2002) 41-50.

[11] F. Li, J.D Pilgrim, C. Dabeedin, A. Chebbo, R.K. Aggarwal, Genetic algorithms for optimal reactive power compensation on the national grid system. Power Systems, IEEE Transactions on, 20 (2005) 493-500 
[12] K.P. Dahal, S.J. Galloway, G.M. Burt, J.R. McDonald, Generation scheduling using genetic algorithm based hybrid techniques, Power Engineering, LESCOPE'01, Large Engineering Systems Conference (2001) 74 - 78.

[13] V. Miranda, D. Srinivasan, L.M. Proenca, Evolutionary computation in power systems, International Journal of Electrical Power and Energy System, 20(1998) 89-98.

[14] B. Stott, Review of load flow calculation methods, IEEE Proc., vol.62, pp.916-929, 1974.
[15] M R Rashid, M E El-Hawary, Application of computational intelligent techniques for solving the revived optimum power flow problem, Electric Power System Research 79 (2009) 694-702.

[16] J.A. Momoh, R. Adapa, M.E. El-Hawary, A review of selected optimal power flow literature to 1993, part II: Newton, linear programming and interior point methods, IEEE Transactions on Power Systems Vol. 14 (1) (1999) $105-111$. 